\title{
A representação discursiva e visual dos portadores de necessidades especiais nos livros didáticos de língua estrangeira moderna: tendências contemporâneas
}

\author{
Juliana da Silva Passos \\ Universidade Federal do Paraná
}

\begin{abstract}
Resumo
O presente trabalho tem como intuito discutir a tendência contemporânea de representar o portador de necessidades especiais nos livros didáticos de língua inglesa e de que maneira se dão tais representações. Estas se limitam a grupos específicos de portadores de necessidades especiais - em geral os cadeirantes - e são, via de regra, estabelecidas através da linguagem visual unicamente. Interessa-nos discutir quem é o sujeito representado e que tipo de discurso visual se constrói e com que propósitos. Igualmente, interessa-nos o fato destas representações não se construírem no plano da linguagem escrita e quais as possíveis significações destas representações exclusivamente visuais e como estas contribuem (ou não) para a formação da identidade e do discurso social em torno dos sujeitos representados e da deficiência. Palavras Chave: representação; necessidades especiais; material didático.
\end{abstract}

\begin{abstract}
This paper discusses the contemporary tendency to represent people with disabilities in the textbooks of English as second language. Such representations are limited, and they are restricted to specific groups of people with special needs - in general the wheelchair user - and are usually established through visual language only. The focus of this paper is the discussion about who the represented subject is and what kind of visual discourse is constructed and for what purposes. The discussion also extends to the fact that these representations are not built in terms of verbal language. It examines as well the possible meanings of these visual representations by themselves and how they contribute (or not) to the identity formation and social discourse of disability.
\end{abstract}

Keywords: representation; disabilities; textbooks. 


\section{REPRESENTAÇÃO E CONSTRUÇÃO DA IDENTIDADE}

Este artigo se constrói a partir da perspectiva dos Estudos Culturais em Educação. Como um campo de estudos consideravelmente democrático e abrangente tanto em seus objetos quanto em seus recortes teóricos, os Estudos Culturais tornam-se de difícil definição, mas, segundo Culler (1999):

\footnotetext{
Em sua concepção mais ampla, o projeto dos estudos culturais é compreender o funcionamento da cultura, particularmente no mundo moderno: como as produções culturais operam e como as identidades culturais são construídas e organizadas, para indivíduos e grupos, num mundo de comunidades diversas e misturadas, de poder do Estado, indústrias da mídia e corporações multinacionais (Culler, 1999: 49).
}

Compreender como se constroem as identidades culturais dentro dos mais diversos contextos sociais é de fundamental importância para desnaturalizar e entender tais identidades exatamente como aquilo que são: construções discursivas. Após séculos de crença no determinismo biológico que buscava causas naturais para o comportamento humano, mapeado de acordo com características genéticas, hoje se compartilha do consenso da determinação cultural em detrimento de heranças biológicas (Passos, 2008: 34).

Atualmente o discurso cultural predomina amplamente sobre as teorias baseadas no determinismo biológico. Isto porque ainda que existam necessidades entendidas como inerentes a todo e qualquer ser humano, existem também divergências em relação às quais seriam tais necessidades. A alimentação, o sono e a reprodução, por exemplo, são algumas destas carências definidas biologicamente, mas como se realizarão dentro de cada sociedade é extremamente variável, e isto será parte da nossa identidade (Passos, 2008: 35).

A identidade é formada por fatores simples, como a maneira como dormimos ou nos alimentamos, até complexas relações de como nos percebemos no mundo e como percebemos nossos semelhantes. Algumas coisas nos são legadas e outras construídas ao longo de nossa existência, nos diferentes sistemas culturais pelos quais somos interpelados. Família, escola e mídia são apenas alguns destes sistemas culturais que determinarão aquilo que somos através da identificação ou não identificação com suas representações (Hall, 2005: 13; Woodward, 2006:42).

A representação engloba as práticas de significação e os sistemas simbólicos pelos quais os significados se constroem, posicionando-nos como sujeito (Woodward, 
2000:42). A identificação ou não-identificação com estas representações é uma das principais relações estabelecidas dentro destes sistemas culturais e determinante na formação destas identidades e das relações com o outro (Woodward, 2000:55). Um exemplo claro deste processo pode ser percebido pela recepção das representações veiculadas, sobretudo, pela mídia televisiva. A televisão apresenta os mais variados padrões estéticos e de comportamento: comportamento sexual, moda, linguagem, padrões de beleza, etc. Tais posturas se popularizam ou não através de processos de identificação: diferentes comportamentos são enaltecidos ou inferiorizados e, de acordo com a relação que estabelecemos com o veículo de comunicação em questão, incorporaremos ou não determinados padrões (Passos, 2008: 36). Tais representações não passam de criações discursivas que podem passar a ter um status de verdade através de um processo de legitimação social e naturalização, que irá mascarar o fato de que representações são apenas uma possibilidade de discurso. Nas palavras de Said,

Isso é bastante evidente no caso da moda. Por que perucas, golas de renda e sapatos altos afivelados aparecem e desaparecem, num período de décadas? Parte da resposta tem a ver com a utilidade e parte com a beleza inerente da moda. Mas se concordamos que todas as coisas na história, bem como a própria história, são criadas pelos homens, veremos como é grande a possibilidade de que a muitos objetos, lugares ou tempos sejam atribuídos papéis e significados que adquirem validade objetiva só depois ${ }^{l}$ de essas atribuições terem sido feitas. Isso vale sobretudo para coisas relativamente incomuns, como estrangeiros, mutantes ou comportamento "anormal" (Said, 2007: 90-91).

Assim, as mais diversas representações que nos interpelam através dos diferentes sistemas culturais "povoam o imaginário e, de maneira implícita, estabelecem-se com força nas crenças de verdade das sociedades" (Passos, 2009: 54). Interessa aos estudos culturais a investigação de como tais discursos de representação fabricam discursivamente os sujeitos e ao mesmo tempo como estas construções constituem os sujeitos modernos e determinam suas relações. Como exemplo disto pode-se observar a tese de doutoramento de Eunice Aita Isaia Kindel (2003), A natureza no desenho animado ensinando sobre homem, mulher, raça, etnia e outras coisas mais, comentada por Wortman e Veiga-Neto (2001) em Estudos culturais da ciência e educação:

Essa autora tem lidado com efeitos constitutivos que as representações contidas nesses desenhos animados têm sobre as crianças, posto que: a bruxa do filme A pequena sereia é

\footnotetext{
${ }^{1}$ Itálico presente no original. Said se utiliza do itálico para destacar o fato das criações humanas adquirirem significados só após a inserção no meio social, e não nas suas gêneses.
} 
gorda; o rei "mau" do filme $O$ Rei Leão é mais escuro que o "bom"; e a personagem Pocahontas, do filme de mesmo nome, é magra, branca e graciosa. Como a autora ressalta,

muitos personagens carregam de forma negativa uma representação da diferença, seja ela de gênero, de raça ou de etnia. (Wortman \& Veiga-Neto, 2001: 104-105)

A representação inclui práticas e sistemas simbólicos pelos quais os significados são produzidos, posicionando os seres como sujeito. É por meio destes significados contidos nas representações que atribuímos sentidos às experiências e ao que somos. Em grande parte, esses sistemas simbólicos tornam possível o que somos e aquilo no que podemos nos tornar. Entendida como um processo cultural, a representação estabelece identidades coletivas e individuais. Os discursos e os sistemas de representação determinam os lugares a partir dos quais os indivíduos se posicionam e a partir de onde falam (Woodward, 2000: 17). Por isso a importância da representação dos vários grupos sociais na mídia, na publicidade e nos livros didáticos, fazendo com que os pertencentes aos diversos grupos sociais, representados nas mais inúmeras posições, possam se identificar e não ter suas identidades suprimidas ou inferiorizadas por um discurso que não os inclui ou apresenta uma representação estigmatizada.

As profundas relações entre as representações escolares e a formação de identidades individuais e coletivas têm levado educadores a formular projetos educacionais que se contraponham às características que fazem com que a escola reforce desigualdades da atual estrutura social (Moreira \& Silva, 2002: 33).

Como reflexo destas mudanças de mentalidade, o Ministério da Educação introduziu os pacotes de tecnologias políticas, intitulados de Parâmetros Curriculares Nacionais, ou PCN, desenvolvidos em um amplo contexto de discussões e produção de saberes. O discurso de base dos parâmetros curriculares brasileiros defende a democratização da escola, e, com isso, aponta significativas reformas no sistema educacional, na escola e na prática docente. Os PCN também exprimem novas visões e representações sobre o mundo e o outro (BRASIL, 1997). Essas mudanças no sistema educacional contribuem para criar novos olhares da coletividade sobre o diferente, sobretudo ao produzir representações sociais novas, desenvolvendo novos campos epistêmicos em torno do outro e das formas de diferença e diversidade social e cultural.

Alterar a representação social é influir em percepções e comportamentos, uma vez que esta tem caráter simbólico, significante e construtivo, no sentido de viabilizar a ocorrência dos fatos, de acordo com a maneira como se representam (Rangel, 2004: 62). 


\section{A REPRESENTAÇÃO DOS PORTADORES DE NECESSIDADES ESPECIAIS NOS LIVROS DIDÁTICOS DE LEM}

A partir das novas políticas de inclusão, criaram-se também novas necessidades. Tais políticas procuram incluir ao máximo os portadores de necessidades especiais nas escolas regulares, reduzindo ao mínimo o número de frequentadores das escolas especiais. Tais políticas são válidas especificamente para o ensino público e regular, mas refletem uma mentalidade de época, na qual a inclusão é vista como positiva e, inclusive, necessária (Colucci, 2004). A partir disso, as tentativas de inclusão repercutem dentro dos mais diversos contextos, sendo estes educacionais ou não.

A presença de indivíduos outrora excluídos dos inúmeros contextos sociais faz com que aconteçam mudanças, frequentemente em caráter emergencial. A mais evidente dessas modificações é a adaptação do espaço físico com base em conceitos de acessibilidade, uma vez que, não havendo a facilidade de acesso físico do indivíduo, torna-se ainda mais difícil o já complicado processo de inclusão. Porém, a simples mudança no espaço e a inclusão física destes sujeitos não fazem com que os alunos portadores de necessidades especiais se adaptem ao sistema educacional e social.

Mudanças arquitetônicas podem ser feitas em caráter de emergência, mas mudanças de mentalidade requerem muito mais tempo e esforço. Enquanto o espaço físico pode ser modificado com alguma facilidade de um ano para o outro, as pessoas continuam reproduzindo comportamentos antigos durante anos. Repetem-se as ideias e os contextos sociais dos quais os sujeitos foram excluídos no passado e dos quais serão potencialmente exclusos novamente. Isto acarreta, muitas vezes, no fracasso escolar dos alunos para os quais a escola não foi pensada.

Uma primeira evidência da exclusão deste sujeito, como parte do contexto escolar, é a sua não representação nos livros didáticos. Ao mesmo tempo em que inúmeros grupos sociais de gênero e étnicos estão lá representados, o portador de necessidades especiais, ao não se encontrar nesses materiais, não se identifica como um membro pertencente àquele grupo. O uso de imagens em livros didáticos tem passado por uma crescente valorização como recurso visual para auxiliar o aluno na compreensão dos textos, por sua linguagem estar aproximada do contexto do aluno, na construção dos sentidos e na possível veiculação de ideologias e culturas por meio das imagens. Esses fatores podem incidir em diversas áreas como, por exemplo, na formação do professor, que deverá saber também como trabalhar com as mensagens visuais e os designers 
responsáveis pelo projeto gráfico do livro didático, que deverão trabalhar com esses fatores dentro de uma tendência contemporânea de inclusão discursiva dos sujeitos.

Para iniciar uma inclusão efetiva do portador de necessidades especiais no ambiente educacional, e, posteriormente, no mercado de trabalho, faz-se completamente necessária uma mudança também nas representações destes indivíduos nos materiais didáticos, o que já aparece como uma tendência contemporânea que analisaremos a partir deste momento.

Para isso, faremos um estudo de caso com base no material "Teens Club", série de 4 livros voltados para o ensino de inglês para o público de crianças entre 11 e 13 anos, iniciantes no estudo do idioma e com os quais trabalhei durante o período de 2006 a 2010. A nova versão do livro foi lançada em 2010, enquanto que a versão anterior data do início dos anos 90. No primeiro livro da série somos apresentados a alguns personagens, que estarão presentes até o último livro e cujas vidas escolares darão mote para as unidades e lições do livro. Abaixo seguem as duas versões da "turma":

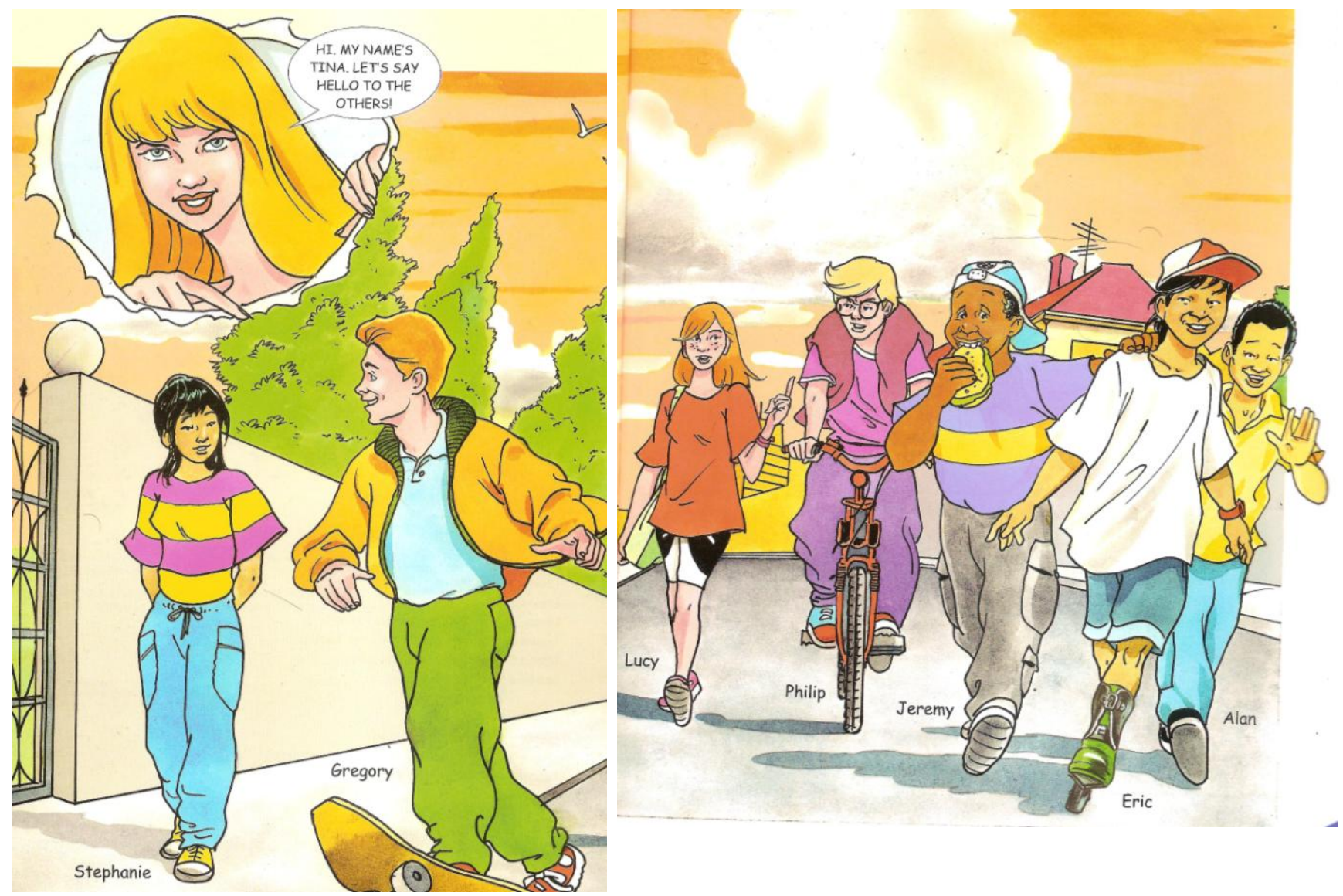

Figura 1: "TEENS CLUB 1" - VERSÃO ANTIGA 

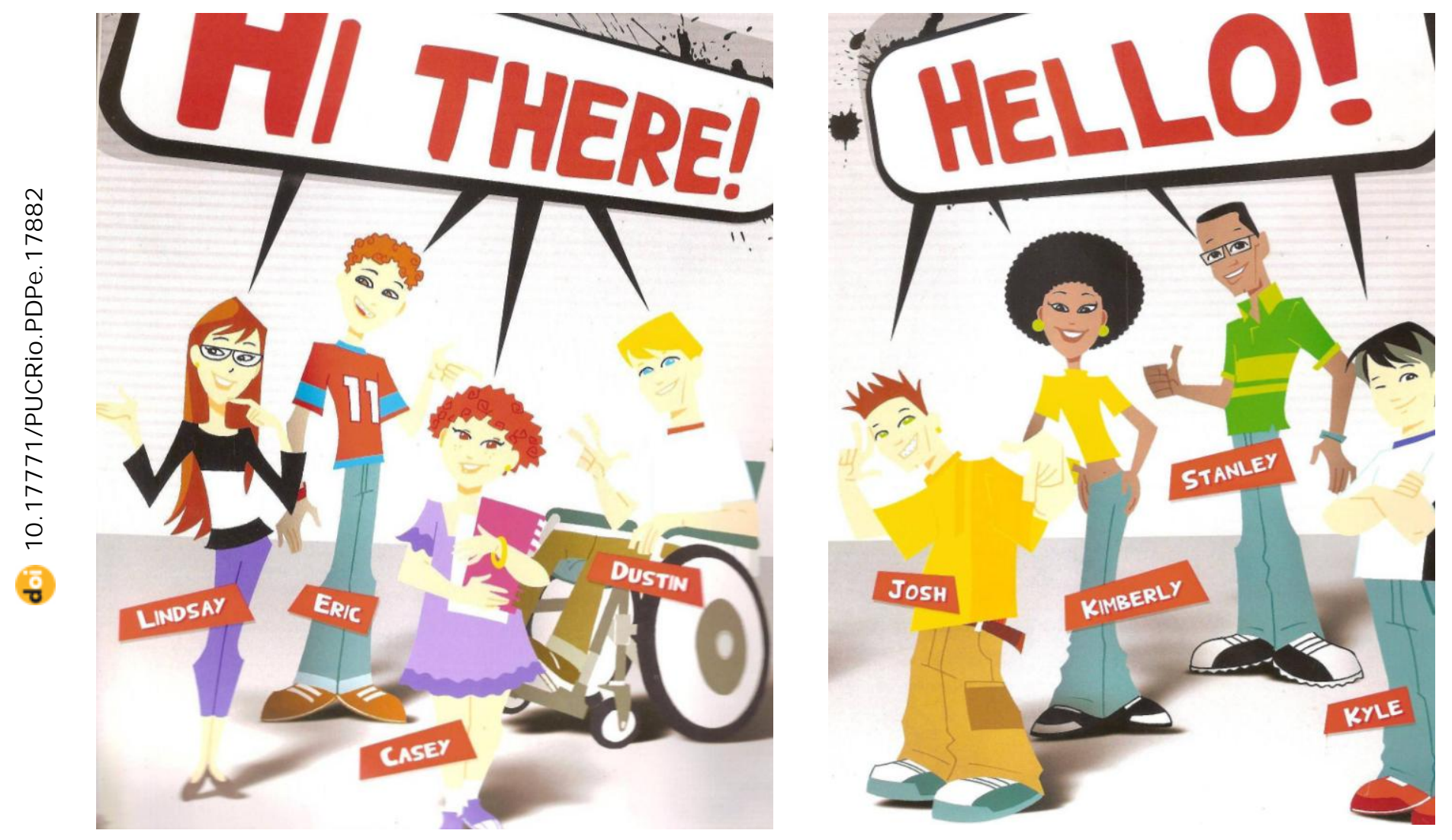

Figura 2: "TEENS CLUB 1" - 2010

Em vários aspectos, podemos percebemos uma configuração parecida no grupo, formado, nas duas versões, por oito crianças, sendo estas três meninas e cinco meninos. Na versão de 2010, uma das meninas, Kimberly, aparece representada como negra e um dos meninos, Dustin, é um cadeirante. As duas diferenças marcam uma preocupação com a representação e a inclusão social. Na primeira versão do livro podemos perceber a já existente preocupação com a representação de etnias diversas, porém a inclusão do portador de necessidades especiais aparece como algo diferente e novo, podendo ser apontado como uma tendência contemporânea.

Também nota-se uma modificação nas características gráficas das representações. No primeiro livro, temos ilustrações feitas à mão, com traços orgânicos e uma linguagem remetendo às histórias em quadrinhos das décadas de 1980-1990. Já a nova versão apresenta ilustrações vetoriais remetendo ao contexto do mundo digital do jovem atual. Essa mudança de linguagem nas representações visuais, buscando uma 
aproximação da identidade cultural para quem ela foi produzida - estudantes entre $11 \mathrm{e}$ 13 anos - é uma forma de compreender melhor a mensagem visual expressa no livro.

Diferentemente da maior parte das representações que temos encontrado na mídia, aqui, o cadeirante não aparece nem como uma figura vitimizada, como um sofredor, nem como um exemplo de superação, mas como um menino normal para sua idade, o que podemos ver nas duas imagens seguintes.

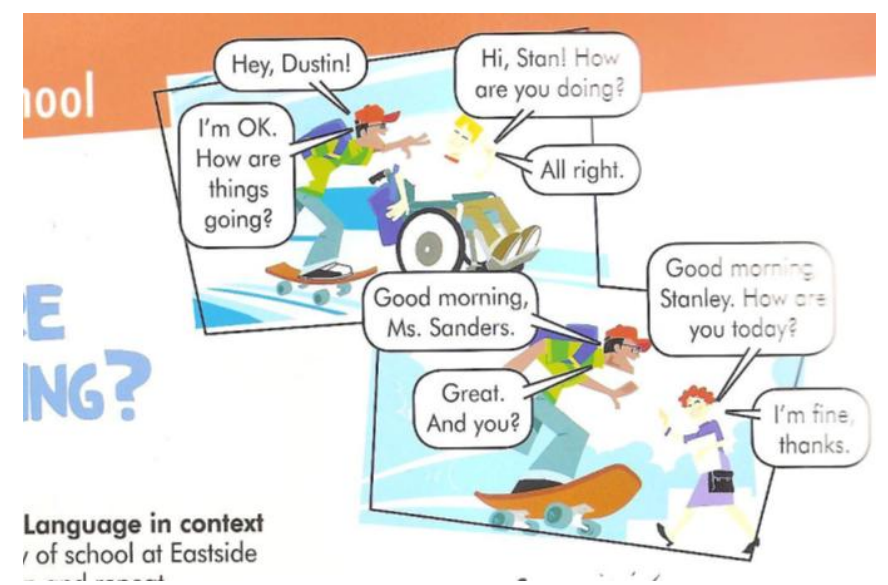

Figura 3

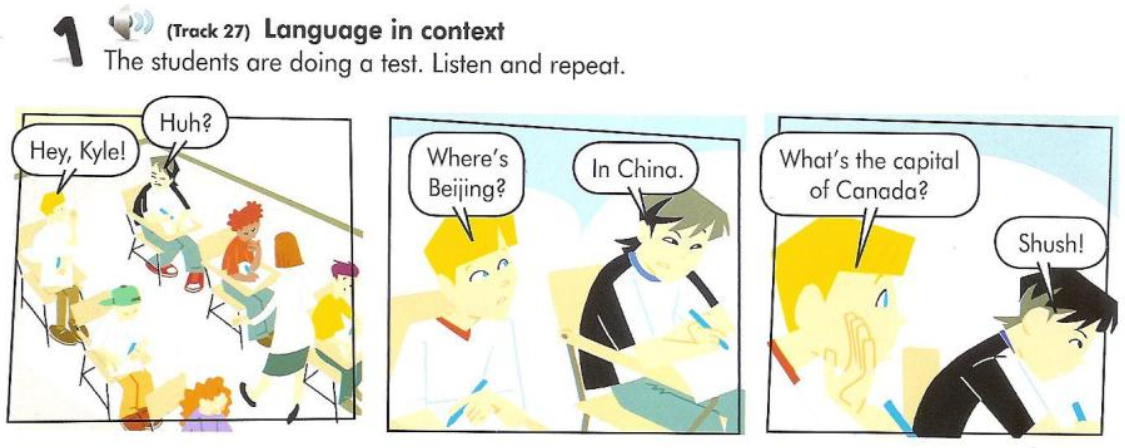

Figura 4

Note-se que na figura 4, temos a personagem Dustin "colando" em uma prova escolar, destacando uma atitude passível de ser encontrada no ambiente escolar, sem diferenciá-lo com uma atitude mais nobre que engrandeça ou vitimize a figura do portador de necessidades especiais. Destacamos também o espaço representado na figura 4. Percebemos que se trata de uma sala de aula tradicional, com cadeiras dispostas em longas fileiras, todas voltadas para frente da sala. Dustin senta em uma 
carteira regular como todos os outros alunos. A representação ignora que, em um contexto real, o aluno precisaria de uma carteira adaptada e, se os assentos estivessem seguindo a disposição apresentada, Dustin não poderia ficar sentado ao fundo da sala, uma vez que teria problemas de acessibilidade para alcançar o lugar que lhe foi determinado.

Dustin também é representado como um menino autônomo e independente, conforme podemos ver na figura que se segue.

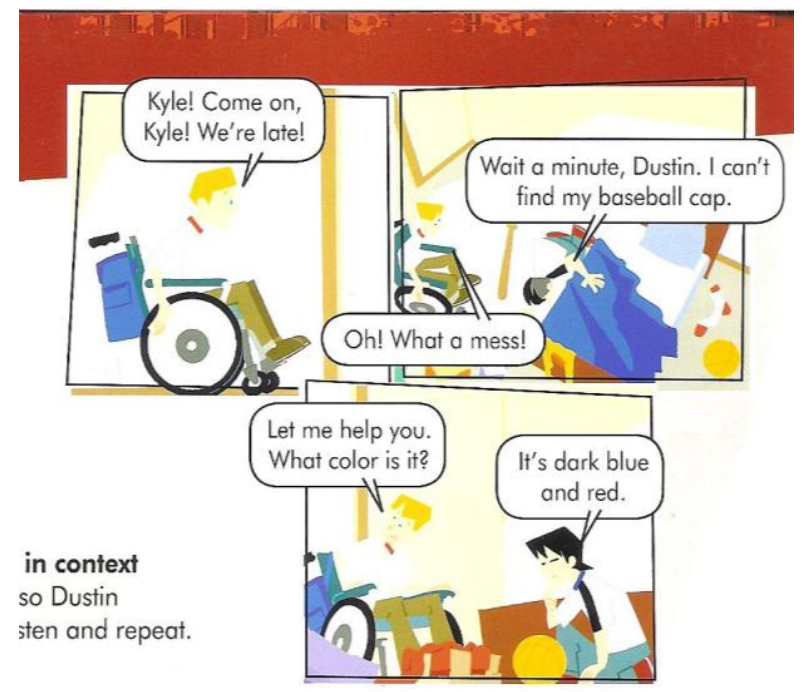

Figura 5

$\mathrm{Na}$ figura 5, percebemos Dustin reclamando do atraso e destacando a desorganização do amigo, o que chama a atenção pelo fato de que, mesmo com uma deficiência motora e maiores dificuldades de locomoção, Dustin é capaz de cumprir horários e organizar-se no espaço de maneira eficiente. Além disto, em nenhuma das imagens percebemos o aluno sendo auxiliado fisicamente pelos colegas, o que sugere sua boa adaptação e autonomia, lhe garantindo mobilidade e independência.

\section{“Os silêncios de Dustin"}

Cabe chamar a atenção para os momentos em que Dustin não é representado. Em vários momentos do livro, ele, e com ele a representação de uma identidade do sujeito portador de necessidades especiais, é excluído. Como se o sujeito com aquelas características pudesse pertencer a alguns contextos, mas ser vetado em outros. Dustin 
ainda aparece como único, sem pares em seu contexto. Em momentos do livro nos quais várias pessoas aleatoriamente são representadas, não encontramos nenhum outro portador de necessidades especiais (ver figura 6).

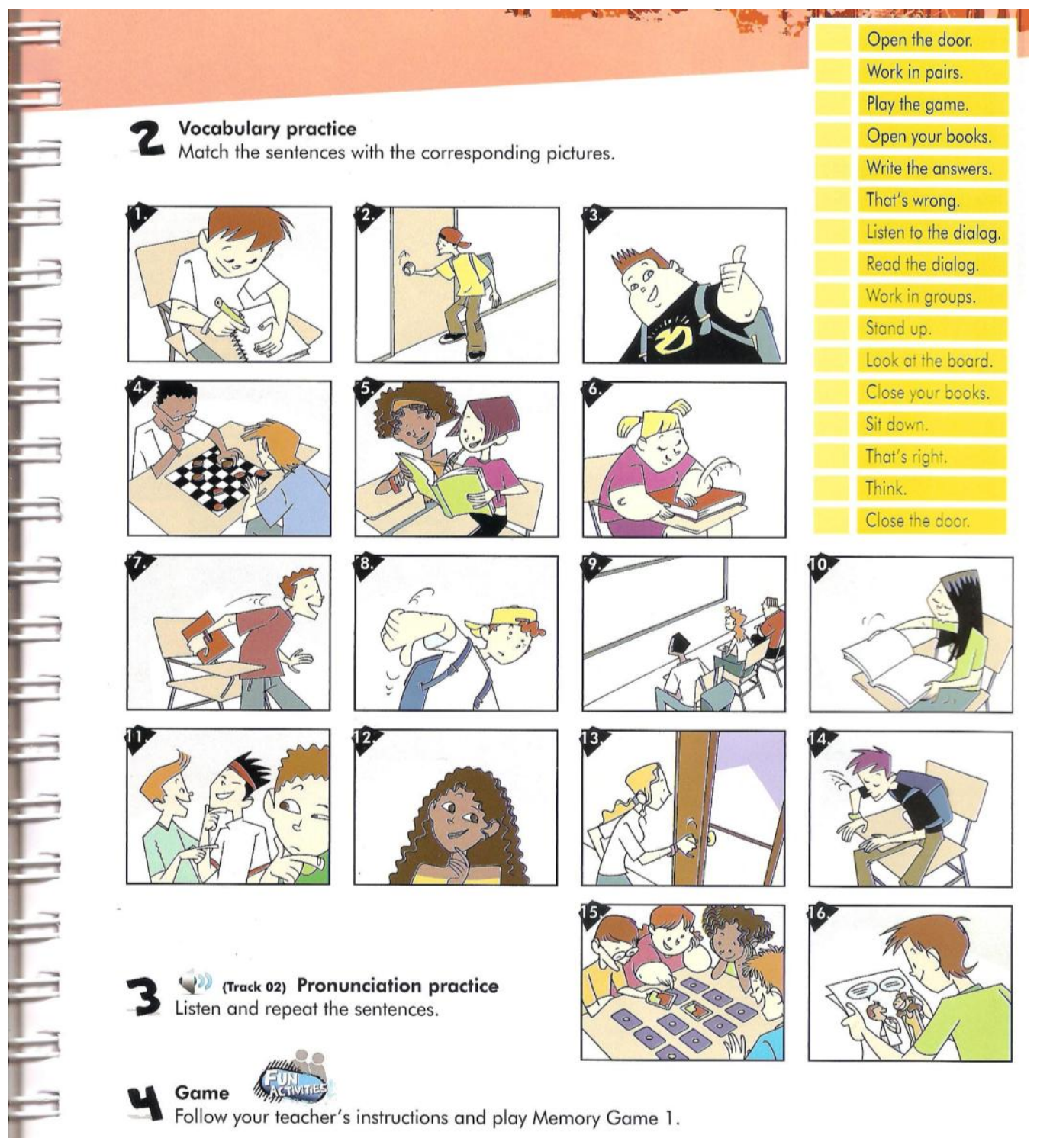

Figura 6

Dustin ainda é completamente excluído da unidade que tem esportes, atividades físicas e materiais esportivos como tema.

Devemos chamar a atenção para o fato de que o enredo da série gira em torno de pequenos romances entre algumas das personagens, assunto do qual Dustin também não faz parte (ver figura 7). 


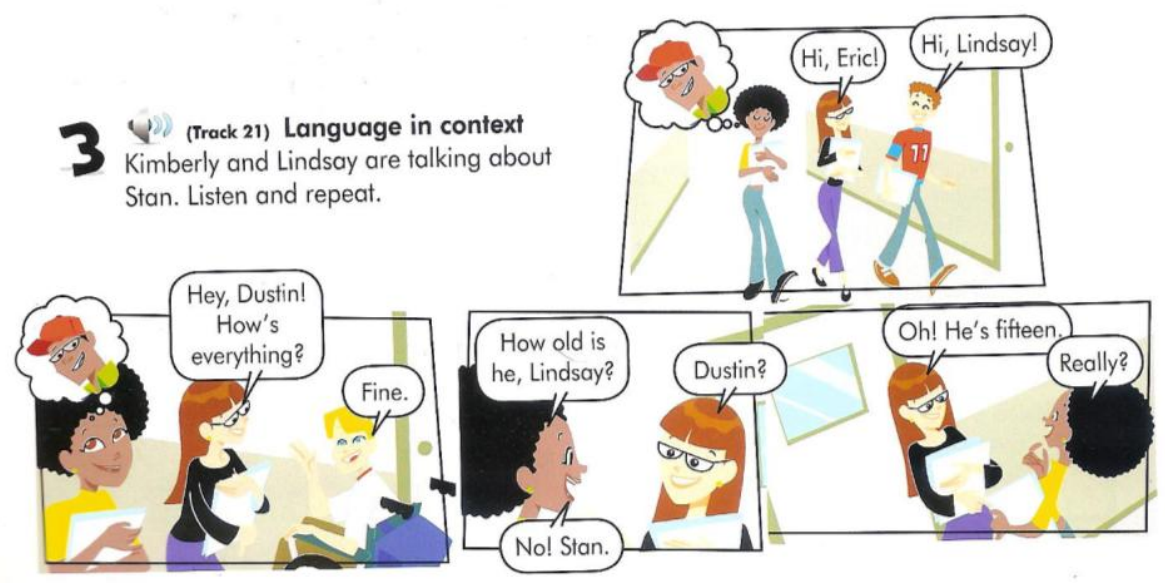

Figura 7

\section{CONCLUSÃO}

Dustin, o cadeirante, aparece como o único representante de um grupo de pessoas com necessidades especiais. Podemos constatar nos inúmeros livros da mesma editora, que, quando existe a representação deste grupo, ela é sempre feita através da imagem de um cadeirante, ou seja, todos os outros portadores de outras necessidades especiais parecem continuar invisíveis para os atores do sistema educacional. Não podemos negar que a simples representação de Dustin já figura como um grande avanço para um sistema educacional que se propõe mais democrático, mas é um grande avanço especialmente por ser um começo para outras transformações. Ainda há muitos a serem incluídos, em todos os sentidos.

A representação do portador de necessidades especiais aqui é feita exclusivamente de maneira pictórica. A diferença de Dustin jamais ganha voz, jamais se transforma em discurso verbal. Não existe nenhuma menção da sua diferença e de suas necessidades, o que parece um sinal de que se evitam temas polêmicos em sala de aula. Percebemos que, a cada vez que a questão da deficiência poderia se tornar um tema para debate em sala, como na relação com os esportes e atividades físicas e ainda nos relacionamentos amorosos, a figura de Dustin simplesmente desaparece. Dustin não é representado verbalmente e parecem ser podadas quaisquer oportunidades de que a personagem torne-se assunto para os alunos. Isto evita, dentro do livro, os problemas que um portador de necessidades especiais encontra fora dos livros. Dustin acaba sendo representado, mas ao mesmo tempo sua diferença é anulada. 
As políticas de representação dos diversos grupos não têm a intenção de apagar as diferenças e sim de abrir espaço para a convivência e aceitação da diversidade, o que não é o que acontece neste caso. Podemos dizer que é um avanço que um portador de necessidades especiais esteja representado dentro do livro didático, uma vez que, de alguma forma, estas representações, através dos olhinhos curiosos dos alunos, aos poucos vão chegando ao imaginário. Por outro lado, parece haver um esforço contrário para que esta representação da diferença passe o mais despercebido possível à visão dos alunos.

Evidência disto parece ser que durante o primeiro semestre de trabalho com este novo material, não ouvi uma única observação dos alunos sobre o fato de Dustin ser diferente ao usar uma cadeira de rodas. É como se Dustin estivesse estado lá sempre. Ou como se ele nunca tenha estado lá. A representação, como fator formador de identidade, prescinde da marca da diferença, caso contrário, é uma "falsa representação", ou seja, uma representação que passa despercebida e, portanto, não representa. Nas palavras de Woodward, as identidades "são formadas relativamente a outras identidades, relativamente ao 'forasteiro' ou ao 'outro', isto é, relativamente ao que não é” (Woodward, 2000: 49). Se não existe marca da diferença, não existe a representação da diferença, muito menos a incorporação e a problematização da diversidade.

E ressalto aqui a importância fundamental da representação não apenas do diferente, mas da sua diferença, porque, como bem colocou Tomaz Tadeu da Silva:

\begin{abstract}
A identidade e a diferença são estreitamente dependentes da representação. É por meio da representação, assim compreendida, que a identidade e a diferença adquirem sentido. É por meio da representação que, por assim dizer, a identidade e a diferença passam a existir. (...) É também por meio da representação que a identidade e a diferença se ligam aos sistemas de poder. Quem tem o poder de representar tem o poder de definir e determinar a identidade. (...) Não é difícil perceber as implicações pedagógicas e curriculares dessas conexões entre identidade e representação. (Silva, 2000: 91-92)
\end{abstract}

Através da representação da diferença, a educação é capaz de oferecer aos sujeitos a oportunidade de desenvolver a capacidade de crítica e questionamento dos sistemas dominantes. Assim, talvez sejamos capazes de mudar a história. Primeiramente, a história daqueles que já estão bem adaptados ao sistema escolar e que, passando por uma mudança de mentalidade, poderão enxergar a diferença com outros olhos. E, sobretudo, a história daqueles até então excluídos, que encontrarão um 
contexto de inserção diferente, mais aberto e quiçá acolhedor, além de conseguirem se projetar nas mais diversas posições sociais, em vez do fado da exclusão.

\section{REFERÊNCIAS}

BRASIL (1997). Parâmetros curriculares nacionais / Secretaria de Educação Fundamental. - Brasília : MEC/SEF.

Colucci, C. (2004). Cresce a inclusão escolar de deficientes. Folha Cotidiano/Folha de S. Paulo, 22 fev. p. C5

Cuder, A. C. (2000). Teens' Club v. 2. São Paulo: CNA. (2010). New Teens' Club v. 1. São Paulo: CNA.

Culler, J. (1999). Teoria Literária: uma introdução. São Paulo: Beca.

Hall, S. (2005). A identidade cultural na pós-modernidade. Rio de Janeiro : DP\&A.

Joly, M. (1996). Introdução à Análise da Imagem. São Paulo: Papirus.

Kindel, E. A. I. (2003). A natureza no desenho animado ensinando sobre homem, mulher, raça, etnia e outras coisas mais... Porto Alegre, UFRGS, Faculdade de Educação (Tese de Doutorado).

Moreira, A. F. \& Silva, T. T. (2002). Sociologia e Teoria Crítica do Currículo. In: (orgs.) Currículo, Cultura e Sociedade. São Paulo: Cortez.

Passos, J. S. (2008). Identidade e Formação de Profissionais de Letras: a contribuição de Stuart Hall. Revista X, vol.1.

(2009). Entre Evas e Marias: a representação feminina em Dorotéia. Curitiba, UFPR, Programa de Pós-graduação em Letras. (Dissertação de Mestrado) em Estudos Literários.

Moscovici, A. (1978). A representação social da psicanálise. Rio de Janeiro: Zahar.

Rangel, M. (2004). Pesquisa de representação social como forma de enfrentamento de problemas socioeducacionais. Aparecida: Ideias \& Letras.

Said, E. (2007). O Orientalismo. São Paulo: Cia das Letras.

Silva, T. T. (2000). A produção social da identidade e da diferença. In: SILVA, T. T. (Orgs.). Identidade e diferença: a perspectiva dos estudos culturais. Petrópolis: Vozes.

Woodward, K. (2000). Identidade e diferença: uma introdução teórica e conceitual. In: Silva, T. T. (Orgs.). Identidade e diferença: a perspectiva dos estudos culturais. Petrópolis: Vozes. 
Wortmann, M.L.C.; Veiga-Neto, A. (2001). Estudos culturais da ciência e educação. Belo Horizonte: Autêntica.
A AUTORA
Juliana da Silva Passos é licenciada em Letras Português-Inglês (2006) pela Universidade Federal do Paraná, pesquisadora na área de linguística aplicada desde 2003, mestre em Letras - Estudos Literários (2008) pela UFPR e doutoranda em Letras - Estudos Literários pela mesma universidade. Atua há oito anos como professora de inglês.
E-mail: julicwb@yahoo.com.br 